\title{
Editorial
}

\section{Avanço da Psicopatologia Fundamental. O pensamento de Manoel Tosta Berlinck más allá}

Gisálio Cerqueira Filho*

Neste número da Revista Latinoamericana de Psicopatologia Fundamental ainda lateja a ausência de Manoel Tosta Berlinck. Mas agora de forma a impulsionar a todos nós, colegas da Associação Universitária de Pesquisa em Psicopatologia Fundamental - AUPPF, pesquisadores e estudantes de distintos programas de pós-graduação, a debruçarmo-nos no aprofundamento dos temas tão amados e estudados por ele. Um texto, entre outros, é precisamente "Catástrofe e representação - Notas para uma teoria geral da Psicopatologia Fundamental" (1999) onde Manoel trabalha no sentido de avançar na demonstração de que é "a partir da catástrofe que surge a linguagem". Dito de outro modo, é a partir do sofrimento que se fala e se escreve. Como diz Ana Maria Rudge em editorial no número de dezembro de 2016: "ele [Manoel T. Berlinck] escreveu sobre o mito freudiano pouco conhecido de forma muito esclarecedora, o mito que se encontra no manuscrito de

* Universidade Federal Fluminense - UFF (Niterói, RJ, Brasil). 
1915, descoberto tardiamente e publicado apenas em 1985, Neuroses de transferência" (p. 600).

Há vários outros conceitos e temáticas que mereceriam a nossa atenção e aprofundamento no sentido de levar a obra de Manoel más allá... Por exemplo "miscigenação por mistura e por justaposição" (Berlinck, 2001), "Insuficiência Imunológica Psíquica" (Berlinck, 1997), "método clínico" (Berlinck, 2010), "a incidência da psicanálise em intensión e extensión", "ethos e pathos", para dar apenas alguns exemplos.

Vale ressaltar um dos temas mais fascinantes que Manoel tangenciava nas suas reflexões, logo ele, que era Doutor em Sociologia. Interrogava-se como e quando, sem prejuízo da clínica propriamente dita, poderíamos avançar na interpretação heurística das relações entre psicanálise e cultura (ideologia), poder, autoridade, tendo como cenário as manifestações estéticas (literatura, poesia, teatro, pintura, escultura, arquitetura, cinema, mídias etc.). Manoel Berlinck, que além de ser psicanalista clínico, realizou uma bela carreira profissional como sociólogo, obtendo o título de Mestre em Sociologia pela Escola de Sociologia e Política de São Paulo, e depois PhD. (com pós-doc.) pela Cornell University, EUA. Foi Diretor do IFCH-UNICAMP

432 e sócio-fundador do CEBRAP. Erudito, cultivava certo sprit de finesse, combinado com leve ironia e senso de humor.

Transformar o luto que vivemos pela perda irreparável do amigo e colega Manoel em trabalho de criação, é levar adiante o desejo de aprofundar os temas em que trabalhava em nossas pesquisas, em nossas orientações, em nossas dissertações e teses, num movimento pulsante que bem merece a expressão "Manoel más allá". Cabe a nós, pesquisadores da AUPPF, e sobretudo aos mais jovens, realizarmos um inventário da obra, das concepções teóricas, dos conceitos operados por Manoel na rotina do seu trabalho intelectual diário. Valeria também refletir sobre o autor como intelectual criativo, suave e gentilmente engajado, comprometido com o amor e o buen vivir.

Com S. Freud poderíamos designar a vivência em João Pessoa, Paraíba, durante o nosso primeiro congresso sem Manoel, com a expressão Das Hunheimlich que Paulo Cesar de Souza traduz como "o estranho inquietante". ${ }^{1}$

Assim, experimentamos na cidade de João Pessoa o caráter invasor da "morte imperfeita" que, fiel à expressão de João Guimarães Rosa, tem algo

${ }^{1}$ Paulo Cesar Souza é o tradutor da obra de Freud para a Companhia das Letras. 


\section{EDITORIAL}

de descomunal. A experiência dessa morte é algo da vivência profunda de um sofrimento que não acaba, mas que de repente muda e transforma-se em alegria das mais genuínas. Enquanto tal não ocorre, temos a angústia. Para Elias Canetti (1988) "a hipocondria é o troco miúdo da angústia e a angústia, para distrair-se, procura e encontra nomes" (p. 32). Todavia, para Manoel Berlinck (2010, 2012), o "estranho inquietante" aparece na clínica como "obscuro surpreendente".

E uma tal relação com esse "obscuro surpreendente" afastaria o

(...) conhecimento objetivo, afastaria igualmente o conhecimento intuitivo e o conhecimento por fusão mística. $\mathrm{O}$ conhecimento como neutro, pressuporia uma relação estranha a toda exigência de identidade e de unidade, ou mesmo de presença. (comunicação oral)

Assim,

(...) relacionar-se com o obscuro surpreendente sem desvelá-lo significa muito precisamente que o enigmático no neutro não pertence à luz. Pertence a uma "região" estranha a essa, a descoberta que se realiza na e pela luz. O obscuro surpreendente não cai sob o olhar, sem estar, no entanto, escondido do olhar: nem visível, nem invisível ou, mais exatamente, desviando-se de todo o visível e de todo o invisível. O obscuro surpreendente, aquele para o qual a clínica nos desperta, é muito mais imprevisível do que pode sê-lo o futuro, mesmo o futuro não predito, pois, tal como a morte, ele escapa a toda apreensão, exceto à fala, mas na medida em que esta não é uma apreensão, não é uma captura. Eis então o essencial na clínica: falar o obscuro surpreendente, acolhê-lo na fala mantendo-o obscuro é precisamente não apreendê-lo, não compreendê-lo, é recusar-se a identificá-lo por essa captura objetiva que é a visão, a qual captura, embora à distância. Viver com o obscuro surpreendente diante de si (o que significa dizer também: viver diante do obscuro e diante de si como obscuro) é entrar nessa responsabilidade da fala que fala sem exercer qualquer forma de poder, inclusive esse poder que se realiza quando olhamos, já que, olhando, mantemos sob nosso horizonte e em nosso círculo de visão — na dimensão do visível/invisível — aquilo e aquele que está diante de nós. Clinicar é, sem vínculo, vincular-se ao obscuro surpreendente e perigoso, ao caso clínico como fundamento da terapia e da pesquisa psicopatológica. (comunicação oral)

Nos termos propostos por Jacques Lacan e aludindo à clínica em intensión e à clínica em extensión, o nosso congresso de 2016 nos solicitou em igual medida a vincularmo-nos, sem vínculo, ao obscuro surpreendente e perigoso da dessubjetivação como morte imperfeita. Não foi simples, nem fácil. 


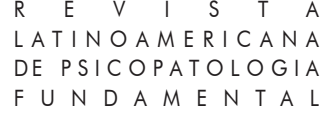

De fato, Manoel estava doente, mas ninguém sabe o dia exato da morte de cada qual. Todavia, Manoel Tosta Berlinck realizou a proeza maior de falecer às vésperas do Congresso de Psicopatologia Fundamental de João Pessoa, surpreendendo-nos a todos e todas com o Hunheimlich da sua "morte imperfeita". Grande Manoel!

\section{Referências}

Berlinck, M. T. (1997). A insuficiência imunológica psíquica. Boletim de Novidades da Livraria Pulsional, 10(103), 5-14.

Berlinck, M. T. (2010). O Método Clínico: projeto temático de pesquisa. São Paulo: AUPPF - CNPq. Também anotações (Vinicius Neder) do minicurso sobre o Método Clínico oferecido no III Congresso Internacional de Psicopatologia Fundamental e IX Congresso Brasileiro de Psicopatologia Fundamental, 4 a 7 de setembro de 2008, Niterói, RJ, Br.

Berlinck, M. T. (2012). O Neutro. Tempo Psicanalítico, 44(1), 183-199.

Berlinck, M. T.; Koltai, C.; Canongia, A. I. (2001, dez.). Esquizofrenia e miscigenação. Revista Latinoamericana de Psicopatologia Fundamental, 4(4), 11-29.

Canetti, E. (1988). O outro processo (as cartas de Kafka a Félice). Rio de Janeiro: Espaço e Tempo, 1988. [Ver ainda Zischler, H. (2005). Kafka vai ao cinema. Rio de Janeiro, RJ: Jorge Zahar.

Citação/Citation: Cerqueira Filho, G. (2017, setembro). Editorial. Avanço da Psicopatologia Fundamental. O pensamento de Manoel Tosta Berlinck más allá. Revista Latinoamericana de Psicopatologia Fundamental, 20(3), 431-435. http://dx.doi.org/10.1590/1415-4714.2017v20n3p431.1

Editores do artigo/Editors: Profa. Dra. Ana Maria Rudge e Profa. Dra. Sonia Leite

Recebido/Received: 18.6.2017/ 6.18.2017 Aceito/Accepted: 30.6.2017 / 6.30.2017 


\section{EDITORIAL}

Copyright: (C) 2009 Associação Universitária de Pesquisa em Psicopatologia Fundamental/University Association for Research in Fundamental Psychopathology. Este é um artigo de livre acesso, que permite uso irrestrito, distribuição e reprodução em qualquer meio, desde que o autor e a fonte sejam citados / This is an open-access article, which permits unrestricted use, distribution, and reproduction in any medium, provided the original authors and sources are credited.

\section{Gisálio Cerqueira Filho}

Sociólogo e cientista político, graduado e licenciado em Ciências Sociais na FNFI(UB), hoje Universidade Federal do Rio de Janeiro - UFRJ (Rio de Janeiro, RJ, Br); Professor Titular de Teoria Política (aposentado) na Universidade Federal Fluminense - UFF (Niterói, RJ. Br), atuando nos Programas de Pós-graduação do ICHF-UFF; Doutor em Ciências Humanas pela Universidade de São Paulo - FFLCH-USP (São Paulo, SP, Br) com pós-doc. na Biblioteca Nacional de Lisboa, Portugal; Mestre em Ciência Política pelo Instituto Universitário de Pesquisa do Rio de Janeiro - IUPERJ (Rio de Janeiro, RJ, Br) com especialização em Métodos e Técnicas de Pesquisa pela Fundação Getúlio Vargas - FGV-RJ (Rio de Janeiro, RJ, Br); Professor Titular de Sociologia (aposentado) na Universidade Cândido Mendes - UCAM (Rio de Janeiro, RJ, Br); Professor Associado Avançado de Ciência Política (aposentado) na Pontifícia Universidade Católica do Rio de Janeiro - PUC-Rio (Rio de Janeiro, RJ. Br), onde foi Diretor do Departamento de Sociologia e Política; Membro da Associação Universitária de Pesquisa em Psicopatologia Fundamental - AUPPF (São Paulo, SP, Br), do Research Committee on Sociology of Law - RCSL (Oñati [Gipuzkoa] España), da Associação Nacional de História - ANPUH (São Paulo, SP, Br). Vasta obra publicada no Brasil e no exterior. Editor de PASSAGENS. Revista Internacional de História Política e Cultura Jurídica. http://www.historia.uff.br/ revistapassagens/

Rua Bom Pastor, 107/901 - bloco 1 - Tijuca

20251-060 Rio de Janeiro, RJ

gisalio@superig.com.br

This is an open-access article, which permits unrestricted use, distribution, and reproduction in any medium for non-commercial purposes provided the original authors and sources are credited. 